\title{
O ATP e os Atropelos da Química
}

\section{Carlos CorrêA* *}

uso vulgarizado de certos termos, como "ligações ricas em energia" e "compostos muito calóricos", que muitos autores utilizam ao tratar de bioenergética, acompanha uma série de erros que circulam na Internet, nomeadamente a ideia de que a cisão de ligações químicas liberta energia, de que a energia libertada em reações químicas resulta da cisão de uma dada ligação nos reagentes, esquecendo as ligações formadas nos produtos da reação. Neste artigo investiga-se a origem destes erros, apresentam-se exemplos da sua intensa difusão e, para evidenciar a sua inconsistência, analisam-se algumas reações muito simples.

Quando ensinei Química Médica a futuros médicos, há cerca de quatro décadas, verifiquei que os alunos estranhavam que para partir ligações químicas fosse necessário fornecer energia às moléculas e argumentavam com o caso do ATP, cuja energia fornecida às células proviria da quebra de "ligações ricas em energia"!

Segundo estas ideias erradas, a energia libertada numa reação proviria da quebra de ligações químicas ditas "de alta energia" presentes em compostos "ricos em energia", como os carbo-hidratos, o ATP e outros.

O que sucede, afinal, é antes uma libertação de energia que resulta de um balanço, a nível molecular, entre as energias das ligações partidas e ligações formadas e de outros factores de menor grandeza, como a deslocalização electrónica, os efeitos estereoquímicos e os efeitos indutores. Sob o ponto de vista termodinâmico, a energia associada a uma reação química (a energia de Gibbs da reação) é o resultado da diferença entre as energias de formação de Gibbs dos produtos e dos reagentes. Não tem qualquer significado associar a energia posta em jogo numa reação à ruptura das tais ligações ditas "ricas em energia".

Verifiquei, mais tarde, que o mesmo erro circulava no ensino secundário e cheguei mesmo a fazer uma série de ações pedagógicas para professores de Biologia em escolas secundárias do norte do país, acompanhado pelo Dr. Adalmiro de Castro e Prof. Moradas Ferreira, com o objectivo de debater um pouco os aspetos energéticos da formação e ruptura de ligações químicas e esclarecer o caso da reação exotérmica de hidrólise do ATP (Adenosine TriPhosphate), Figura 1.

Procurei averiguar a causa desta ideia errada e consultei alguns livros de Bioquímica e verifiquei que, no geral, não aparecem os mesmos erros no tratamento da hidrólise do ATP, mas alguns autores deixam escapar frases que podem ser interpretadas erradamente, como se se libertasse energia quando se partem ligações químicas:

a) "(...) a ruptura de uma ligação entre dois grupos fosforilo, num número suficiente de moléculas de ATP, liberta essa quantidade de energia" [1] b) "A ligação pirofosfato do ATP é a fonte de energia dos processos endergónicos que ocorrem na célula" [2]

O que deveria ser dito era que a) "(...) a hidrólise (cisão por ação da água) de uma ligação entre dois grupos fosforilo, num número suficiente de moléculas de ATP, liberta essa quantidade de energia" e que b) "A hidrólise (cisão por ação da água) da ligação pirofosfato do ATP é a fonte de energia dos processos endergónicos que ocorrem na célula".

c) Na Wikipédia [3] o assunto é tratado corretamente, chamando a atenção para a reação global e não para a ruptura de uma simples ligação: "Deve-se levar em conta que a quebra do ATP não é simplesmente um rompimento de ligações químicas. Sabe-se que a destruição de ligações químicas é um processo endotérmico, e isso seria uma contra-
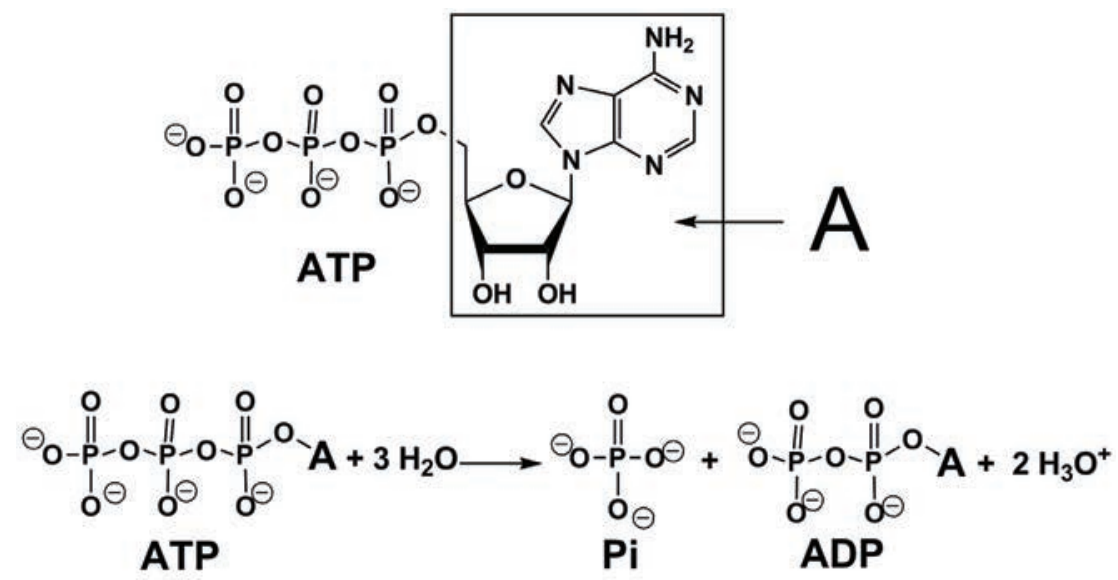

Figura 1 - Hidrólise do ATP 
dição. Na verdade, a transformação da ATP em ADP + P é uma hidrólise, ou seja, a água é um dos reagentes desse processo. A formação de ligações covalentes no final da transformação libera mais energia do que a absorção na quebra das ligações presentes entre os átomos das moléculas de ATP e água. Dessa forma, a reação global acaba se tornando exotérmica"

Apesar disto, deixa escapar uma frase que pode levar a interpretações erradas: "A energia é armazenada nas ligações entre os fosfatos", o que não é verdade, pois as ligações químicas não armazenam energia, mas exigem energia para serem quebradas.

É de salientar o livro Bioquímica Geral [4], que critica o uso da designação "ricos em energia" nos seguintes termos: "É comum dizer-se que os compostos cuja variação de $\Delta G^{0}$ de hidrólise é muito negativa são ricos "em energia" e que as ligações que são hidrolisadas são "ricas em energia" o que não é nada evidente. Acontece unicamente que a entalpia livre padrão de formação (actualmente "energia de formação de Gibbs") dos produtos é mais baixa que a entalpia livre padrão de formação dos reagentes". Na edição anterior, referia igualmente "(...) designada por "ligação rica em energia", designação que não é muito feliz uma vez que é a energia libertada na hidrolise que é elevada e não a energia da ligação".

No sítio [5] trata-se adequadamente o assunto e até se chama a atenção para a ideia errada, ensinada algumas vezes em Biologia, de se libertar energia por quebra de ligações: "We have already seen that chemical energy is released when chemical bonds form (...) Energy is released when ATP breaks down to produce ADP + ortophosphate. So, are we being told that in biology the breaking of a bond releases energy? Is this the opposite of what we learn in chemistry? That is a very good question to ask your teachers".

$\mathrm{Na}$ realidade liberta-se energia na hidrólise do ATP, mas essa energia provém principalmente de um balanço entre a energia gasta na quebra de al- gumas ligações e a energia libertada na formação de outras ligações.

L. Stryer, no seu livro de Bioquímica [6] refere a origem destas designações enganosas: "O ATP é muitas vezes denominado um fosfato de alta energia e as suas ligações fosfoanidrido (ligações das pontes de oxigénio para os átomos de fósforo) referidas como ligações de alta energia. Deve notar-se que não há nada de especial em relação às ligações propriamente ditas. Elas são ligações de alta energia no sentido de que se liberta muita energia quando elas são hidrolisadas, pelas razões apresentadas acima. O termo de Lipmann "ligação de alta energia" e o seu símbolo $\sim P$ para um composto contendo um grupo fosfato com elevado potencial de transferência são notações vivas, concisas e úteis. De facto, esta linguagem figurada de Lipmann (Lipmann's squiggle) contribuiu muito para estimular o interesse na bioenergética".

Apesar disto, continua a usar o termo incorrecto "ligação de alta energia" como se a energia libertada resultasse da quebra de determinada ligação. Fritz Albert Lipmann foi um notável professor e investigador, Prémio Nobel da Fisiologia e Medicina de 1953, com H.A. Krebs, pela descoberta da coenzima A. O artigo onde foram introduzidas estas designações intitula-se "Metabolic Generation and Utilization of Phosphate Bond Energy" [7] e nele Lipmann parece reduzir a hidrólise de ésteres fosfóricos à quebra de ligações.

Ao esclarecer o termo "Potencial de um Grupo" refere, na página 102: "These biological interesting linkages designed to transfer groups with loss of energy will be called "weak" linkages based on the usual chemical nomenclature with respect to cleavage processes. If, with cleavage, large amounts of energy can be made free (negative change in free energy - atualmente designada energia de Gibbs de reação - the tendency to burst the linkage is relatively great: thus a weak linkage (small affinity). If little energy is freed with cleavage, or energy has even to be furnished, the linkage is called strong (large affinity). Now, very often the biochemist and likewise the synthetic organic chemist is not interested to talk so much about the weakness of the linkage by which a group is bond as about the energy accumulated in the linkage (o que está errado, como se explica mais à frente neste artigo). Instead of emphasizing the negative, the escape of energy through cleavage, he wants to emphasize the positive, the largeness of energy present in the linkage before cleavage, which determines the group potential, the escaping tendency of the group".

É evidente que este modo incorrecto de localizar numa ligação a energia libertada num processo químico e centrar a reação na rutura de uma ligação, esquecendo a formação de novas ligações, em nada diminuiu os valiosos trabalhos de Lipmann.

Será que estas designações figuradas de Lipmann são concisas e úteis, como refere Stryer? Vejamos como foram interpretadas por inúmeros autores que publicam na Internet. Seria impossível referir todas as fontes que difundem estes erros, mas vou transcrever algumas ao acaso:

1) "En las células, la energía que recibe o cede el ATP es la contenida en el enlace entre su último fosfato y el resto de la molécula. El enlace se forma durante la síntesis de ATP: incorporan así energía, la que se cede cuando el enlace se escinde (Fig. B)" [8]

2) "ATP é (...) Os 2 últimos radicais fosfato estão ligados ao resto da molécula através de ligações de alta energia. A quantidade de energia libertada por cada uma dessas ligações por mole de ATP é de aproximadamente $11 \mathrm{kcal}$ nas condições de temperatura e concentração de reagentes do músculo durante o exercício" [9]

3) "A ligação entre os grupos de fosfato $P \sim P$ ou $P \sim P \sim P$, indicada por linhas curvas envolvem uma grande quantidade de energia potencial armazenada" [10]

4) "A quebra da ligação química que o unia à molécula libera uma quantidade de energia que é utilizada nos processos bioquímicos; 
nesse caso, o ATP fica sendo ADP $+P+$ energia para os processos vitais" [11]

5) "When the third phosphate bond is created, it immediately is broken and energy is released (...)" [12]

6) "When broken, these bonds release about 7.3 kilocalories per mole (...)" [13]

7) "The energy needed to carry out the reaction involving the substrates is generated by breaking the phosphate-phosphate bond in the ATP" [14]

8) "The energy that is stored within an ATP molecule is released for your muscles to use when the bond between the second and third phosphate groups is broken" [15]

9) "Because of the substantial amount of energy liberated when it is broken, the bond between the second and third phosphates is commonly described as a "highenergy" bond" [16]

10) "The breaking of chemical bonds between the $2^{\text {nd }}$ and $3^{\text {rd }}$ phosphate groups provides most of the chemical energy used by a cell" [17]

11) "As these chemical bonds are broken (as ATP is converted into ADP and an inorganic phosphate) the energy release is $12 \mathrm{kcal} / \mathrm{mol}$ in vivo (...)" [18]

12) "The chemical bond between the phosphate groups and the adenosine is a high-energy bond. This means that energy is released when the bond is broken"[19]

13) "At the energy-requiring site, the last phosphate group in the tail is broken off and the energy in the bond liberated" [20]

14) "Most of the energy in ATP is contained in the bond between the second and third phosphate in what is known as the pyrophosphate bond. When the bond is broken, the scattered energy is used immediately to power a necessary process that the cell is doing" [21]
15) "The P-O-P bond is an ordinary covalent bond, but it releases about $7.3 \mathrm{kcal} / \mathrm{mol}$ of free energy (under standard biochemical conditions) when it is broken" [22]

16) "When ATP supplies energy to a reaction, it is usually the energy in the last bond that is delivered to the reaction" [23]

17) "When a cell needs energy, it breaks this bond to form adenosine diphosphate $(A D P)$ and a free phosphate molecule" [24]

18) "The breaking of chemical bonds between the $2^{\text {nd }}$ and $3^{\text {rd }}$ phosphate groups provides most of the chemical energy used by a cell" [25]

19) "The energy is stored in the P-P-P or the phosphate bond which is released when the bond is broken and ATP converts into ADP (...)" [26]

20) "These molecules can transport energy because phosphate bonds contain a lot of potential energy, which is released when they are broken" [27]

21) "(..) when the chemical bond between phosphate groups in ATP is broken, energy is released (...)" [28]

22) "ATP provides energy by breaking its bond between its phosphates. It will break off one phosphate, and the energy from the bond breaking will give another reaction energy. The ATP molecule is unstable with 3 phosphates, so it wants to break its bond with that third phosphate to lower its energy level... so when it finds another molecule that needs energy, it donates it by breaking that third phosphate bond" [29]

Todas estas transcrições mostram que muitos autores de textos, apesar de competentes na sua área científica, usam uma linguagem defeituosa ou mesmo errada, contribuíndo para a divulgação de ideias deturpadas sobre assuntos básicos e importantes em Ciência. É constante a ideia errada de que há energia acumulada nas ligações químicas (por isso falam em "ligações ricas em energia", em compostos muito energéticos) e de que da cisão dessas ligações se obtém energia. Até indicam a ligação onde se localiza a energia libertada!

Tem uma certa piada ver as consequências físicas destas ideias absurdas. Se assim fosse, não existiam moléculas (nem agregados atómicos gigantes, como o diamante, o quartzo e muitos outros), pois a atomização das moléculas e desses agregados era fortemente exotérmica (ruptura das ligações...), a que acrescia o enorme aumento de entropia do sistema e do Universo. Todas as substâncias que existem seriam termodinamicamente instáveis, só sobrevivendo (até um dia) devido à sua estabilidade cinética.

Os átomos só se mantinham ligados até que alguém lhes fornecesse a energia de activação necessária para se separarem. Os foguetes no S. João teriam iniciado a dissociação do $\mathrm{O}_{2} \mathrm{e}$ $\mathrm{N}_{2}$ atmosféricos, com tremendo aquecimento global; as panelas metálicas teriam explodido nas mãos dos cozinheiros e nós próprios teríamos sido volatilizados após termos dado um espirro suficientemente forte para activar as reações de decomposição dos compostos que nos constituem.

Mas não sejamos tão drásticos e analisemos casos simples, como a combustão fortemente exotérmica do di-hidrogénio no seio do ar, formando água:

$$
2 \mathrm{H}_{2}(\mathrm{~g})+\mathrm{O}_{2}(\mathrm{~g}) \rightarrow 2 \mathrm{H}_{2} \mathrm{O}(\mathrm{g})
$$

Segundo a terminologia errada que encontrei na Internet teríamos um "composto rico em energia" (o combustível) com ligações $\mathrm{H}-\mathrm{H}$ "ricas em energia" cuja cisão libertava grande quantidade de calor! Se compararmos as energias das ligações $\mathrm{H}-\mathrm{H}$ $(436 \mathrm{~kJ} / \mathrm{mol})$ e $\mathrm{O}=\mathrm{O}(499 \mathrm{~kJ} / \mathrm{mol})$ concluímos que, afinal, quem é rico em energia é o $\mathrm{O}_{2}$ ! A energia libertada vem do $\mathrm{H}_{2}$ ou do $\mathrm{O}_{2}$ ? $\mathrm{Na}$ hidrólise do ATP quem é "rico em energia", o ATP ou a água? O que se passa é uma reação entre o di-hidrogénio e o dioxigénio da qual resulta a libertação de energia. É um disparate querer fazer aqui intervir qualquer composto "rico" ou "pobre em energia". 
Quando dois átomos de hidrogénio se ligam libertam-se $436 \mathrm{~kJ} / \mathrm{mol}$. De onde vem essa energia se não há ligações (de alta energia...) que possam partir?

$$
\mathrm{H}(\mathrm{g})+\mathrm{H}(\mathrm{g}) \rightarrow \mathrm{H}_{2}(\mathrm{~g})
$$

Quando uma molécula de di-hidrogénio reage com um átomo de hidrogénio:

$$
\mathrm{H}_{2}(\mathrm{~g})+\mathrm{H}(\mathrm{g}) \rightarrow \mathrm{H}(\mathrm{g})+\mathrm{H}_{2}(\mathrm{~g})
$$

não se transfere qualquer energia para o exterior sob a forma de calor. Então a cisão da "ligação rica em energia" H-H não liberta energia?! Vejam até onde nos conduziam estas ideias absurdas postas a circular no mundo biológico!

As ligações químicas não contêm qualquer quantidade de energia. As ligações mais fortes são as mais "pobres em energia", são as que libertaram mais energia quando se formaram. A energia libertada ou consumida numa reação química resulta, fundamentalmente, de um balanço entre a energia libertada na formação das ligações nos produtos e da energia consumida na quebra das ligações nos reagentes. É um disparate querer associar a energia posta em jogo numa reação química a esta ou àquela ligação quando há várias ligações postas simultaneamente em jogo.

Todas as confusões que enchem a Internet e alguns manuais resultaram do uso de termos correntes, como substâncias "muito energéticas", substâncias "muito calóricas", em que se atribuem calorias às substâncias e não a certas reações em que elas participam. Note-se que estas substâncias conduzem a reações exotérmicas quando reagem com o oxigénio, mas poderão reagir endotermicamente com outros reagentes. Por exemplo, o metano reage com o dioxigénio originando $\mathrm{CO}_{2}$ e $\mathrm{H}_{2} \mathrm{O}$, sendo a reação fortemente exotérmica:

$2 \mathrm{CH}_{4}(\mathrm{~g})+3 \mathrm{O}_{2}(\mathrm{~g}) \rightarrow 2 \mathrm{CO}_{2}(\mathrm{~g})+2 \mathrm{H}_{2} \mathrm{O}(\mathrm{g})$
No entanto, a reação do metano com o dibromo:

$2 \mathrm{CH}_{4}(\mathrm{~g})+\mathrm{Br}_{2}(\mathrm{~g}) \rightarrow 2 \mathrm{CH}_{3}(\mathrm{~g})+2 \mathrm{HBr}(\mathrm{g})$

é endotérmica $\left(\Delta H_{\mathrm{f}}\right.$ é de cerca de $+289 \mathrm{~kJ} / \mathrm{mol}$ ). Esta energia consumida corresponde à diferença entre a energia gasta na cisão de duas ligações C-H (2x414 kJ/mol) e uma ligação $\mathrm{Br}-\mathrm{Br}(193$ kJ/mol) e a energia libertada na formação de duas ligações $\mathrm{H}-\mathrm{Br}(2 \times 366 \mathrm{~kJ} / \mathrm{mol})$. Então, o metano é um composto de "alta" ou de "baixa" energia?!

Igualmente abusivo é localizar a energia nesta ou naquela ligação. Só em certos casos tem interesse, e é possível, particularizar as energias das diferentes ligações, como sucede nas reações de remoção de hidrogénio das posições alílicas de compostos insaturados nos processos de autoxidação de lípidos (Figura 2). Aqui podemos dizer que a remoção mais extensa de hidrogénio nessas posições se deve à menor energia das correspondentes ligações $\mathrm{C}-\mathrm{H}$ (ligações mais fracas).

Como a ligação que se forma é a mesma em ambas as reações, a energia libertada na reação (1) é menor do que a libertada na reação (2), porque a ligação C-H a partir em (1) é mais forte do que em (2). Daqui resulta que a reação (2) é mais rápida que a reação (1), embora nem sempre as reações mais exotérmicas sejam mais rápidas. Em resumo:

a) As designações "compostos e ligações de alta (ou baixa...) energia" não têm qualquer sentido físico e podem levar a conclusões erradas.

b) A ruptura de ligações químicas consome energia, que tem de ser fornecida à molécula.

c) A formação de ligações químicas liberta energia. d) Não tem sentido localizar a energia libertada nas reações químicas em qualquer dos reagentes, muito menos numa dada ligação.

\section{REFERÊNCIAS}

[1] L. S. Campos, "Entender a Bioquímica", Escolar Editora, 2009, 5. a ed. pag. 202.

[2] I. Raw, A. Freedman e L. Mennucci, "Bioquímica, Fundamentos para as Ciências Biomédicas", Mc Graw-Hill do Brasil, 1981, vol. 1, pag. 232.

[3] http://pt.wikipedia.org/wiki/Trifosfato_ de_adenosina (consultado em junho de 2012).

[4] J. H. Weil "Bioquimica Geral", Fundação Gulbenkian, 2000, 2. ${ }^{\text {a }}$ edição, pag. 168.

[5] http://sci-culture.com/advancedpoll/ GCSE/atp.php (consultado em junho de 2012).

[6] L. Stryer, "Biochemistry", W. H. Freeman \& Company, 1981, pag. 241.

[7] F. Lipmann, "Metabolic Generation and Utilization of Phosphate Bond Energy", em Advances in Enzymology and Related Subjects, Interscience Publishers, 1941, 99-162.

[8] http://www.cienciahoy.org.ar/hoy27/ atp.htm (consultado em junho de 2012).

[9] http://www.fade.up.pt/fisiologiageral/ arquivo/bioenergetica.pdf (consultado em junho de 2012).

[10] http://www.ebah.com.br/content/ ABAAAAcacAC/conservacao-energia (consultado em junho de 2012).

[11] http://www.unificado.com.br/novo/didatico/2_EM_RESP_CELULAR.pdf (consultado em junho de 2012).

[12] http://wiki.answers.com/Q/What_is_ ATP (consultado em junho de 2012).

[13] http://www.ehow.com/facts_6727996_ bond-between-ribose-atp.html (consultado em junho de 2012).

[14] http://www.chemguide.co.uk/CIE/section111/learningl.html (consultado em junho de 2012).

[15] http://www.shapesense.com/fitnessexercise/articles/exercise-energy-systems.aspx (consultado em junho de 2012).

[16] http://users.rcn.com/jkimball. ma.ultranet/BiologyPages/A/ATP.html (consultado em junho de 2012).

[17] http://hypertextbook.com/facts/2000/ Amberlqbal.shtml (consultado em junho de 2012).

[18] http://www.newworldencyclopedia. org/entry/Adenosine_triphosphate

Figura 2 - Remoção de hidrogénio das posições alílicas de compostos insaturados nos processos de autoxidação de lípidos 
(consultado em junho de 2012).

[19] http://uww.livestrong.com/article/502849phosphate-groups-glucose (consultado em junho de 2012).

[20] http://www.brooklyn.cuny.edu/bc/ahp/ LAD/C7/C7_atp.html (consultado em junho de 2012).

[21] http://www.chacha.com/question/ does-the-bonds-between-the-phosphate-groups-in-atp-store-largeamount-of-potential-energy (consultado em junho de 2012).

[22] http://www.ncbi.nlm.nih.gov/books/
NBK21737 (consultado em junho de 2012).

[23] http://www.cliffsnotes.com/study_ guide/Chemical-Reactions-in-Metabolic-Processes.topicArticleld277792, articleld-277512.html (consultado em junho de 2012).

[24] http://www.bodybuilding.com/fun/ galanis9.htm (consultado em junho de 2012).

[25] http://www.shmoop.com/photosynthesis/terms.html (consultado em junho de 2012).
[26] http://www.buzzle.com/articles/whatis-atp.html (consultado em junho de 2012).

[27] http://tami-port.suite101.com/what-isatp-a33529 (consultado em junho de 2012).

[28] http://stockdale.kernhigh.org/Sub Webs/teachers/keene/ch_outlines/ Ch09PPT.pdf (consultado em junho de 2012).

[29] http://www.thedrugsafety.com/faq/ ribose-atp (consultado em junho de 2012).

\section{Atualidades Científicas}

\section{NANOTECNOLOGIA PARA ACELERAR A CICATRIZAÇ̃̃O DE FERIDAS}

Um grupo de cientistas na China desenvolveu um material capaz de reduzir o tempo necessário para curar uma ferida. Nos últimos anos têm sido desenvolvidos vários projetos de investigação para estudar as aplicações biomédicas promissoras do quitosano, uma molécula que consegue coagular o sangue de forma eficaz. Bingan Lu e colaboradores, da Universidade de Lanzhou, desenvolveram um método que permite combinar as propriedades benéficas do quitosano com o grafeno, um material constituído por átomos de carbono e para o qual tem sido demonstrado que possui atividade antibacteriana.

A equipa de investigadores misturou grafeno com nanofibras de quitosano-álcool polivinílico (PVA) usando eletrofiação (um processo no qual é aplicada uma carga elétrica para formar fibras muito finas a partir de uma solução). Deste modo, as nanofibras de quitosano combinam-se com o grafeno, formando membranas finas. Essas membranas foram aplicadas em pequenas feridas na pele e, após 10 dias, as feridas tratadas com essa membrana apresentaram uma cicatrização significativamente superior àquelas que foram tratadas sem a membrana.

Para testar o potencial discriminatório do material desenvolvido foram também usadas culturas celulares e demonstrou-se que o grafeno é apenas prejudicial para as células bacterianas, enquanto que as células animais não são afetadas. Os cientistas sugerem que este facto pode ser devido à transferência de eletrões através da membrana celular, desencadeada pelo grafeno, que impedirá as células bacterianas de replicar, dado que os eletrões poderão alcançar o DNA bacteriano e destruí-lo. No caso das células animais isso não acontecerá porque o DNA se encontra protegido por uma segunda membrana (a membrana nuclear) e por isso não é afetado. No entanto, a equipa pretende investigar de uma forma mais aprofundada as propriedades antibacterianas do grafeno para confirmar o mecanismo.

(adaptado de http://www.rsc.org/chemistryworld/News/2012/April/graphene-speeds-up-wound-healing.asp)

Marcelo Vaz Osório (marcelovazosorio@gmail.com) Faculdade de Farmácia da Universidade do Porto

\section{O ANTIGO OCEANO de MAGMA de MercúRIO}

Cientistas que analisaram os dados de fluorescência de raio-X recolhidos pela MESSENGER (MErcury Surface, Space ENvironment, GEochemistry, and Ranging), uma sonda da NASA que orbita o planeta Mercúrio desde março de 2011, identificaram dois tipos de composição bastante distintos das rochas da superfície do planeta. Deste modo, esta descoberta despoletou um enigma planetário: que processos geológicos teriam conduzido a estas diferenças tão significativas nas composições à superfície?

De forma a responder a esta questão, uma equipa do MIT usou os dados composicionais de modo a recriar os dois tipos de rochas em laboratório. Posteriormente submeteu cada rocha sintética a pressões e temperaturas elevadas de modo a simular diversos processos geológicos. Através destas experiências, a equipa verificou que os dados de composição dual apenas podem ser explicados por uma sequência de fenómenos específica: um vasto oceano de magma criou duas camadas de cristais, solidificou e depois eventualmente voltou a fundir em magma que irrompeu na superfície de Mercúrio.

"Dado que a crosta de Mercúrio tem provavelmente mais de 4 mil milhões de anos, o processo descrito teria de ser um fenómeno mesmo muito antigo", afirma Timothy Grove, professor de geologia no MIT, que juntamente com o postdoc Bernard Charlier e Maria Zuber, professora de Geofísica e Ciência Planetária no MIT, publicou os resultados desta pesquisa no Earth and Planetary Science Letters. Larry Nittler, investigador no Carnegie Institution of Washington, que liderou a equipa que originalmente identificou os dois tipos de rochas a partir dos dados da MESSENGER, reconhece que os resultados experimentais da equipa do MIT propõem um cenário bastante provável para a explicação da história inicial de Mercúrio.

(adaptado do artigo de 21/02/2013: Mercury May Have Harbored an Ancient Magma Ocean: Massive Lava Flows May Have Given Rise to Two Distinct Rock Types, http://www.sciencedaily.com/releases/2013/02/130221115808.htm)

Paulo Brito (paulo@ipb.pt) Instituto Politécnico de Bragança 


\section{Submit Now:}

\section{ChemistryOPEN} is one of 11 journals of ChemPubSoc Europe an organisation comprising 16 European chemical societies. www.chempubsoc.eu

\section{Editorial Advisory Board} Chairmen:
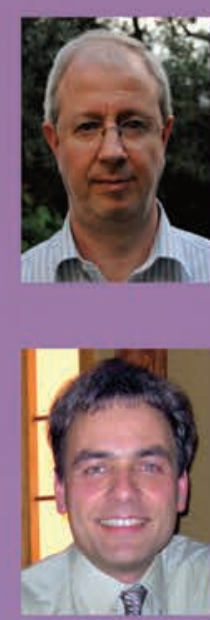

Thomas Wirth, Cardiff University, UK

Editorial Advisory Board Honorary Chairman:

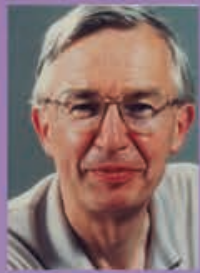

Jean-Marie Lehn, Nobel Prize winner in chemistry in 1987 , Collège de France, Paris / Univ. L. Pasteur, Strasbourg, France
A journal of

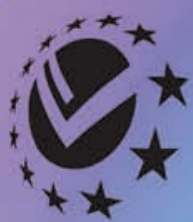

ChemPubSoc Europe

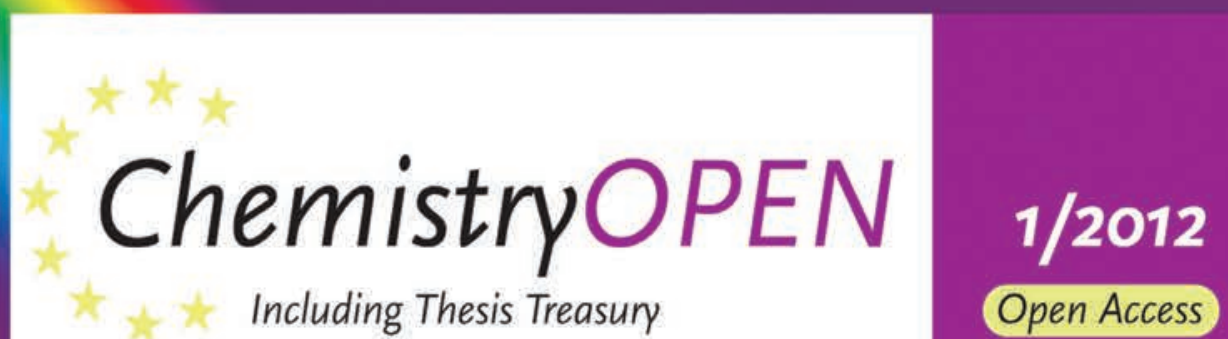

Open Access

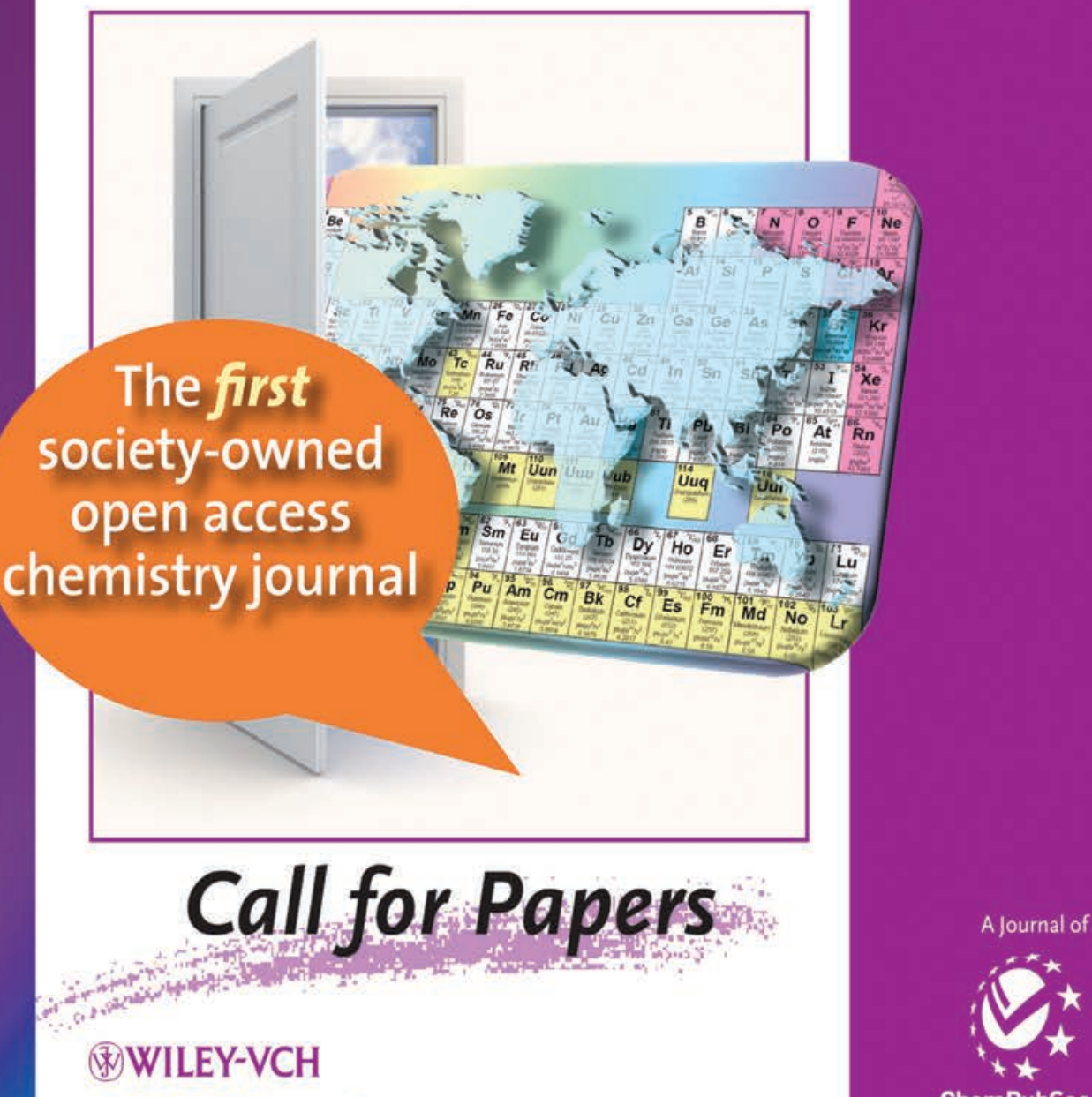

(WILEY Open Access

\section{www.chemistryopen.org}

